Revista Oficial del Poder Judicial

ÓRGANO DE INVESTIGACIÓN DE LA CORTE SUPREMA DE JUSTICIA DE LA REPÚBLICA DEL PERÚ

Vol. 11, n. ${ }^{\circ} 13$, enero-junio, 2020, 363-388

ISSN versión impresa: 1997-6682

ISSN versión electrónica: 2663-9130

DOI: https://doi.org/10.35292/ropj.u11i13.49

\title{
El método de la prueba indiciaria, aplicable para la valoración de indicios y la prueba directa en las sentencias sobre delitos de concusión (colusión), peculado y corrupción de funcionarios (cohecho) ${ }^{1}$
}

The method of circumstantial evidence applicable to the assessment of evidence and the direct evidence in the judgment of collusion, embezzlement and corruption of government officials (bribery)

0 (0)

RAÚl CABALLERO LAURA

Poder Judicial del Perú

(Lima, Perú)

Contacto: rcaballero@pj.gob.pe

https://orcid.org/0000-0003-4005-4241

\section{RESUMEN}

Luego de culminado el juicio oral, en los delitos de concusión (colusión), peculado y corrupción de funcionarios (cohecho)

1 El contexto de investigación en el cual se inserta este artículo es la praxis, la impartición de justicia que he constatado, en mi calidad de funcionario de justicia, como juez del Segundo Juzgado Penal Unipersonal Nacional Permanente Especializado en Corrupción de Funcionarios de la Corte Superior Nacional de Justicia Penal Especializada en el Perú. 
frecuentemente no existe prueba directa. La «prueba indiciaria» debe valorarse utilizando el "principio de sana crítica», desarrollando los elementos de esta: a) la lógica, con sus principios de identidad, contradicción, razón suficiente, tercero excluido; b) las máximas de la experiencia (criterios normativos o reglas no jurídicas);

c) conocimientos científicamente aceptados.

El método de valoración de la prueba indiciaria implica utilizar la «inferencia deductiva», lo cual es adecuado. Este «método de valoración de la prueba indiciaria» debe aplicarse a la valoración de la «prueba directa», por ser más eficaz, para acercarnos a la verdad.

Palabras clave: prueba directa, indicio.

\section{ABSTRACT}

At the end of the hearing, in the judgment of collusion, embezzlement and corruption of government officials (bribery), it is not possible to file direct evidence. The «circumstantial evidence» should use the principles of formal logic: a) principle of identity, principle of contradiction, principle of excluded middle and sufficient reason; b) the standards stemming from experience (normative criteria or non-legal rules); c) scientifically accepted knowledge.

The use of «deductive inference» as a method to interpret evidences is adequate. This «method of evaluating evidence» must be applied to the assessment of "direct evidence», as it is more effective to bring us closer to the truth.

Key words: direct evidence, circumstantial evidence.

Recibido: 25/05/2020 Aceptado: 10/06/2020 


\section{INTRODUCCIÓN}

Actualmente, en el ejercicio de la valoración de los actos de prueba que efectúan los operadores del derecho (jueces penales especializados, fiscales, abogados penalistas y otros), en delitos cometidos por funcionarios públicos, en relación con los delitos de concusión (modalidad de colusión), peculado y corrupción de funcionarios, en la prueba indirecta (indicio) se utiliza pocas veces el «método de valoración de la prueba indiciaria» previsto en el Nuevo Código Procesal Penal (Decreto Legislativo n. ${ }^{\circ}$ 957), que consiste en realizar una evaluación conjunta ${ }^{2}$ de tres requisitos, para darle certeza a una prueba indirecta: a) que el indicio esté probado; b) que la inferencia se base en un razonamiento de enlace, aplicando reglas de la lógica, la ciencia y máximas de la experiencia; y c) si existen indicios contingentes, que sean plurales, concordantes y convergentes, y no se presenten contraindicios consistentes (artículo 158.3, Decreto Legislativo n. ${ }^{\circ}$ 957).

Ello garantiza que la prueba indirecta (de indicios) sea debidamente valorada porque permite enlazar el hecho base (indicio acreditado), que no es materia del elemento fáctico delictivo, con el hecho consecuencia (hecho indiciado), para inferir si ha producido o no el hecho delictivo. Sin embargo, en la realidad, pocas veces se utiliza dicho método de valoración de la prueba indiciaria, en desmedro de la certeza de la prueba indirecta.

De otro lado, inexplicablemente, esta forma de valorar la prueba de indicios, a través del referido método de valoración de la prueba indiciaria, no es utilizada por los operadores del derecho para el análisis de la prueba directa (testigos, peritos, documentos y otros),

2 En el nuevo proceso penal peruano, la valoración de los actos de prueba, surgidos del juicio oral y que constituirán la base de la sentencia, se realizan, primero, en forma individual, y luego, en forma conjunta (artículo 393.2, Decreto Legislativo n. ${ }^{\circ}$ 957, del 29 de julio de 2004). 
lo que ocasiona una ineficaz e insuficiente valoración de la prueba, alejando de la verdad material al juez sentenciador, para emitir una sentencia penal justa.

\section{DESARROLLO DEL TEMA}

\subsection{La prueba}

La Corte Interamericana de Derechos Humanos considera muy relevante la suficiente actuación de actividad probatoria que debe desarrollarse en el juicio oral, con el objetivo de que el juzgador emita una sentencia en justicia. Así:

En la medida que «la demostración fehaciente de la culpabilidad constituye un requisito indispensable para la sanción penal $\aleph^{3}$, dicho principio establece que «el acusado no debe demostrar que no ha cometido el delito que se le atribuye», ya que la carga de la prueba (onus probandi) recae en la parte acusadora ${ }^{4}$. Precisamente por ello, si contra una persona obra prueba incompleta o insuficiente de su responsabilidad penal, «no es procedente condenarla, sino absolverla $\aleph^{5}$, en la medida que para una sentencia condenatoria debe existir prueba plena de dicha responsabilidad ${ }^{6}$ (Ibáñez, 2014, pp. 233-234).

3 Corte IDH (26 de noviembre de 2010. Serie C n. ${ }^{\circ}$ 220). Caso Cabrera García y Montiel Flores vs. México (párr. 182) y Corte IDH (1 de septiembre de 2011. Serie C n. $\left.{ }^{\circ} 224\right)$. Caso López Mendoza vs. Venezuela (párr. 128).

4 Corte IDH (8 de julio de 2004. Serie C n. ${ }^{\circ} 110$ ). Caso Ricardo Canese vs. Paraguay (párr. 154) y Corte IDH (1 de septiembre de 2011. Serie C n. $\left.{ }^{\circ} 224\right)$. Caso López Mendoza vs. Venezuela (párr. 128).

5 Corte IDH (18 de agosto de 2000. Serie C n. ${ }^{\circ}$ 69). Caso Cantoral Benavides vs. Perú (párr. 120) y Corte IDH (26 de noviembre de 2010. Serie C n. ${ }^{\circ} 220$ ). Caso Cabrera García y Montiel Flores vs. México (párr. 183).

6 Corte IDH (18 de agosto de 2000. Serie C n. ${ }^{\circ}$ 69). Caso Cantoral Benavides vs. Perú (párr. 120) y Corte IDH (1 de septiembre de 2011. Serie C n. ${ }^{\circ} 224$ ). Caso López Mendoza vs. Venezuela (párr. 128). 
En nuestro país se efectuaban tradicionalmente dos tipos de controles de las normas: el "control concentrado», a cargo del máximo intérprete de la Constitución Política del Perú (Tribunal Constitucional), y el «control difuso», cuyos responsables son los jueces del Poder Judicial. Sin embargo, dada la doctrina internacional, todos los magistrados en el Perú deben efectuar el «control de convencionalidad ${ }^{7}$, labor también asignada a los jueces de la Corte Interamericana de Derechos Humanos, de la cual nuestro país es signatario.

En el Perú, el derecho a la prueba se considera un derecho fundamental, pues está contenido implícitamente en el derecho al debido proceso $^{8}$ y, según el Tribunal Constitucional (2003, fundamentos jurídicos 133-135), este derecho se encuentra taxativamente previsto en la carta magna.

Asimismo, ello representa «doble exigencia» para el juez, quien primero debe revisar las pruebas aportadas por el Ministerio Público, así como las pruebas ofrecidas por todas las partes, ya sean acusados, terceros civilmente responsables, personas jurídicas, terceros civiles o agraviados. En segundo lugar, las pruebas deben ser valoradas con criterios «objetivos» y «razonables» (Corte Suprema de Justicia de la República, 2012, fundamento jurídico 3.3).

7 En cuanto al control de convencionalidad, este era «un ejercicio que la Corte IDH realizaba "al analizar la complejidad del asunto, [...] verifica[ndo] la compatibilidad entre la conducta del Estado y las disposiciones de la Convención [...] deb[iendo] explorar las circunstancias de jure y de facto del caso". En esta primera concepción, el control de convencionalidad se refiere esencialmente a la competencia de la Corte IDH para conocer y decidir un caso aplicando la Convención Americana, tanto en los hechos como en el derecho de cualquier asunto que se le presente y en el cual sea competente» (Corte IDH, 28 de noviembre de 2007, serie C n. ${ }^{\circ}$ 172, párr. 95, como se citó en Ferrer y Pelayo, 2014, p. 64).

8 «Son principios de la función jurisdiccional: [...] La observancia del debido proceso y la tutela jurisdiccional» (artículo 139, inciso 3, Constitución Política del Perú, 1993). 
Por ello, consideramos que, para emitir una sentencia penal - ya sea declarando la condena o la absolución del acusado-, el juez debe efectuar un riguroso y cuidadoso examen en la valoración de los actos de prueba que han surgido del juicio.

\subsubsection{La prueba directa}

Tradicionalmente, se ha diferenciado la prueba directa de la prueba indiciaria, que será utilizada para sustentar una decisión penal derivada del juicio oral.

Normalmente, en el derecho procesal penal peruano, los actos de prueba surgidos del juicio se valoran utilizando las reglas de la sana crítica, que se interpreta aplicable a la valoración de la prueba directa. Como anteriormente señalamos, la norma procesal penal peruana ha dispuesto que «el juez deberá observar las reglas de la lógica, la ciencia y las máximas de la experiencia» (artículo 158.1, Decreto Legislativo n. ${ }^{\circ}$ 957).

Esta norma ha sido interpretada por la Corte Suprema de Justicia de la República (2017) en el siguiente sentido:

La apreciación de la prueba ha de ser conforme a las reglas de la sana crítica (concordancia con los artículos 158.1 y 393.2 del CPP) [...]. Los elementos que componen la sana crítica son: (i) la lógica, con sus principios de identidad [...], de contradicción [...], de razón suficiente [...] y del tercero excluido [...]; (ii) las máximas de la experiencia [...] (criterios normativos o reglas no jurídicas [...]); (iii) los conocimientos científicamente aceptados [...] [Rodrigo Rivera Morales. La Prueba: Un análisis racional y práctico. Editorial Marcial Pons, Madrid, 2011, p. 254] (p. 7924).

La norma referida no alude a que en la valoración de las pruebas directas pueda aplicarse el método de valoración de la prueba indiciaria, lo cual disminuye la rigurosidad del estándar en la profundidad del análisis por el juzgador de la prueba directa. 


\subsubsection{La prueba indiciaria}

\subsubsection{En el Tribunal Europeo de Derechos Humanos}

El Tribunal Europeo de Derechos Humanos, en el caso Phan Hoang contra Francia, sentencia del 25 de diciembre de 1992, y Telfner contra Austria, sentencia del 20 de marzo de 2001, otorga plena validez a la utilización del método de valoración de la prueba por indicios, a través de una deducción o inferencia, en cuanto el objeto no es directamente el objeto constitutivo de delito, sino un hecho intermedio, que es el presuntamente delictivo.

Así, se considera un «hecho base» («hecho indicador» que debe estar plenamente probado) que permite conocer otro «hecho consecuencia» («hecho delictivo», si se acredita el delito) y, para ello, se utiliza un "razonamiento basado en el nexo causal y lógico» (conocido como inferencia). Además, estos indicios deben ser plurales, concomitantes, interrelacionados, como indicios fuertes (Corte Suprema de Justicia de la República, 2006, fundamento jurídico 4).

\subsubsection{En el Tribunal Supremo español}

Conforme al Tribunal Supremo español, en la Sentencia n. ${ }^{\circ}$ 197/199, del 25 de octubre de 1999, la inferencia (en la valoración de los indicios) debe ser razonable (fundamento jurídico 5), y tiene que responder a las reglas de la lógica y la experiencia (Corte Suprema de Justicia de la República, 2006, fundamento jurídico 4).

\subsubsection{En las normas internacionales y en la Constitución Política del Perú}

La Convención Americana sobre Derechos Humanos regula el derecho a la presunción de inocencia. Así, dispone: «2. Toda persona inculpada de delito tiene derecho a que se presuma su inocencia mientras no se establezca legalmente su culpabilidad» (artículo 8, Garantías Judiciales). 
Por tanto, si bien en la Constitución Política del Perú (1993) no se ha establecido expresamente el derecho a probar, considerando que la presunción de inocencia tiene carácter de derecho fundamental (artículo 24, literal e), el derecho a probar está implícito en el derecho a la presunción de inocencia. Por ello, es necesario que el juzgador, al momento de valorar los actos de prueba surgidos del juicio oral, valore eficazmente tanto las pruebas directas como las indiciarias. Ello justifica que el método de valoración de la prueba indiciaria pueda ser utilizado en la valoración de la prueba directa.

\subsubsection{En el Nuevo Código Procesal Penal peruano}

La nueva norma procesal penal peruana (Decreto Legislativo n. ${ }^{\circ}$ 957), del 29 de julio de 2004, contiene dos supuestos en cuanto a la valoración de las pruebas: de un lado, la valoración de la prueba directa ${ }^{9}:$ «1. En la valoración de la prueba el juez deberá observar las reglas de la lógica, la ciencia y las máximas de la experiencia, y expondrá los resultados obtenidos y los criterios adoptados» (artículo 158). De otro lado, la valoración de la prueba indiciaria:

3. La prueba por indicios requiere:

a) Que el indicio esté probado;

b) Que la inferencia esté basada en las reglas de la lógica, la ciencia o la experiencia;

c) Que cuando se trate de indicios contingentes, estos sean plurales, concordantes y convergentes, así como que no se presenten contraindicios consistentes (artículo 158).

Como se recordará, al analizar la prueba directa, adelantamos que la Corte Suprema de Justicia de la República (2017) ha interpretado que, para la valoración de aquella, debe recurrirse a la «sana crítica», a la cual también se refiere el artículo 393.2 del NCPP,

9 No dispone en forma expresa que se refiere a la valoración de la prueba directa, pero se infiere en contraposición con la valoración de la prueba indiciaria. 
y mencionamos los elementos que la componen: la lógica, las máximas de la experiencia y los conocimientos científicamente aceptados.

Se entiende que la Suprema Corte refiere que debe utilizarse esta forma de valoración a la prueba directa. Sin embargo, en relación con la valoración de la prueba indiciaria, la Corte Suprema de Justicia de la República (2010) tiene otro pronunciamiento, pues requiere los siguientes presupuestos:

a) El hecho base o los indicios, que deben estar plenamente acreditados, serán plurales, concomitantes e interrelacionados (sin contraindicios).

b) Debe existir un razonamiento lógico, que se fundamente en las reglas del pensamiento humano, para descubrir el hecho consecuencia (presunto delito), partiendo de la plena probanza del hecho base, es decir, se aplicaría la secuencia: hecho baseinferencia-hecho consecuencia.

c) El órgano jurisdiccional debe detallar el conjunto de indicios y su prueba; además, debe explicar lógica y claramente de qué forma - al partir de un hecho base (no delictivo) - se llega a conocer el hecho consecuencia (delito).

Ante ello, consideramos que la técnica de valoración basada en el principio de la «sana crítica» no solo abarca a la valoración de las pruebas directas, sino también a la de las indiciarias. Aplicando este razonamiento, en la valoración de las pruebas indiciarias se utiliza la inferencia, que no es sino un razonamiento adecuado lógico basado en el método deductivo, es decir, en la valoración de las pruebas indiciarias se emplea el método de valoración de la prueba indiciaria.

Por ello, pese a que el Nuevo Código Procesal Penal no lo refiere expresamente, en puridad, nada impide que a la valoración de la prueba directa pueda aplicársele el método de valoración de 
la prueba indiciaria. En otras palabras, en la prueba directa se utilizarían las inferencias de acuerdo con las siguientes exigencias:

a) Que el acto de prueba (testigo, perito, documento, etc.) esté plenamente probado.

b) Que la inferencia esté basada en las reglas de la lógica, la ciencia o las máximas de la experiencia.

c) Que cuando se trate de actos de prueba directa contingentes, estos sean plurales, concordantes y convergentes, así como que no se presenten contraprueba directa ni indicios consistentes.

De esta forma, se elevará el estándar de certeza en el juzgador, al momento de valorar las pruebas directas, las cuales también pueden complementarse con el análisis de las pruebas indiciarias. Así, a efectos del presente artículo, en los delitos de concusión (modalidad de colusión), peculado y corrupción de funcionarios (en las modalidades de cohecho propio, cohecho impropio, cohecho pasivo específico, cohecho pasivo propio o impropio en el ejercicio de la función policial, cohecho activo genérico, cohecho activo específico y cohecho activo en el ámbito de la función policial), antes de elaborar la sentencia, el juez debe analizar si existe prueba directa o indiciaria. Desde nuestra perspectiva, si existe la prueba directa, debe emplearse el mismo método de valoración que en la prueba indiciaria.

\subsubsection{En la jurisprudencia de la Corte Suprema de Justicia del Perú}

En los delitos de lavado de activos, el método de valoración de la prueba indiciaria, interpretada por la Corte Suprema de Justicia del Perú, ha sido plasmado en pronunciamientos de las Salas Penales Permanente y Transitorias. En este tipo de delitos, la prueba idónea es la indiciaria y requiere los tres presupuestos anteriormente citados de la Corte Suprema de Justicia de la República (2010). 
Posteriormente, con más profundidad, la Salas Penales Permanente y Transitoria de la Corte Suprema de Justicia del Perú desarrollan el estándar de prueba necesario en los delitos de lavado de activos, a través del fundamento jurídico 19 de la Sentencia Plenaria Casatoria n. ${ }^{\circ}$ 1-2017/CIJ-433, del 11 de octubre de 2017.

En dicha sentencia se establece como principios jurisprudenciales de carácter vinculante, entre otros supuestos, que el delito de lavado de activos es un «delito autónomo», por tanto, del «delito fuente», y basta que se acredite la actividad criminal de modo genérico, tal como se deduce del Acuerdo Plenario n. $.^{\circ} 03-2010 / C J-116$, fundamento jurídico 29.

Analizando los fundamentos jurídicos de esta decisión, los magistrados de la Corte Suprema (27 de octubre de 2017) razonaban:

No se requiere, en suma, la identificación de las concretas operaciones delictivas previas; basta la acreditación de la actividad criminal de modo genérico - de un injusto penal- Como no se necesita una condena anterior de la actividad antecedente de la que procede el activo maculado, es suficiente establecer la relación con actividades delictivas y la inexistencia de otro posible origen del mismo [...] (conforme STSE 154/2008, de 8 de abril).

Con este antecedente, en los casos de lavado de activos, advertimos que se enfatiza más aún la técnica de utilizar el método de valoración de prueba indiciaria, porque el delito fuente constituye un elemento objetivo del tipo legal. Por ende, es necesario que se acredite cada uno de ellos; es decir, que se acrediten sospechosas operaciones comerciales o no, que generen incremento patrimonial injustificado, creación de «empresas fantasmas», simulación de actividades económicas, entre otros patrones de comportamientos inusuales en comerciantes. 
Consideramos que este método de valoración de la prueba por indicios (recurrente en los delitos de lavado de activos) es aplicable también a los delitos de concusión (modalidad de colusión), peculado y corrupción de funcionarios.

\subsection{Aplicación del método de valoración de la prueba por indicios a las pruebas directas en los delitos de concusión (colusión), peculado y corrupción de funcionarios (cohecho) del Código Penal peruano}

En el contexto peruano, los delitos elegidos para nuestro análisis, en relación con la prueba directa, son los siguientes:

\subsubsection{Delito de concusión (modalidad de colusión)}

Según el artículo 384 del Código Penal, para que se configure este delito, el funcionario o servidor público, utilizando indebidamente su cargo, en las adquisiciones de las contrataciones públicas, adquisición de bienes, obras, servicios, concesiones o cualquier operación a cargo del Estado, "concierta con los interesados para defraudar patrimonialmente al Estado o entidad $\mathrm{u}$ organismo del Estado». Asimismo, esta defraudación puede ser con o sin afectación patrimonial, según el tipo penal modificado por el Decreto Legislativo n. ${ }^{\circ}$ 1243, de fecha 22 de octubre de 2016.

Además, la jurisprudencia de la Corte Suprema de Justicia de la República aclara hermenéuticamente que la colusión será «simple» (delito de peligro) si se descubre antes de defraudar patrimonialmente al Estado; y será «agravada» (delito de resultado) si se descubre luego de causar perjuicio patrimonial al Estado, en cuyo caso, la prueba idónea es la pericia contable, tal como se puede leer en los fundamentos jurídicos 5-7 de la Casación n. ${ }^{o}$ 661-2016-Piura, de fecha 11 de julio de 2017. 
De este modo, se verifica que la «concertación» no es fácil de acreditar porque requiere ingente actividad probatoria para descubrirla, la cual se construye mediante «indicios», pues casi nunca (salvo contados casos en los que el imputado se acoge al beneficio de colaboración eficaz $)^{10}$ existe prueba directa, por tener la concertación naturaleza clandestina.

En esa línea, se justifica recurrir a la prueba por indicios, ya que, al encontrarnos ante delitos de participación necesaria, debe analizarse tanto el accionar del funcionario o servidor público (intraneus), así como el accionar de los «interesados» (extraneus). A ello se agrega que, dentro de los intraneus, debe analizarse, por ejemplo, la conducta de los titulares de las entidades públicas (gerentes regionales, alcaldes, etc.), los integrantes del comité especial, el gerente de Administración y Finanzas, el gerente de Tesorería, el gerente de Asesoría Legal, entre otros, que intervienen en las autorizaciones de las diversas contrataciones de bienes y servicios, concesiones o cualquier operación estatal.

Como se verifica, en ambas modalidades, la palabra clave es «concertar»; lo que se genera en el ámbito de la contratación pública (Tribunal Constitucional, 2012). Además, debe distinguirse cuándo estamos frente a un delito de peligro y cuándo frente a uno de resultado. Será de peligro «si la concertación es descubierta antes que se defraude patrimonialmente al Estado [...]» (Casación n. ${ }^{\circ}$ 661-2016-Piura, fundamento jurídico 15); por ello, se trata de un delito de colusión simple. Será un delito de resultado «si

10 En el Perú, la institución jurídica de la colaboración eficaz es utilizada por algunos acusados a efectos de obtener sanciones penales de menor rigor que las que les corresponderían de no acogerse a ella, o inclusive exoneración de pena, dependiendo de la calidad de información que suministren al señor fiscal. Pueden acogerse a la colaboración eficaz en diversas etapas del proceso penal (sección VI del Nuevo Código Procesal Penal, Decreto Legislativo n. ${ }^{\circ}$ 957, artículos 472 a 481-A). 
la concertación es descubierta luego de que se causó perjuicio patrimonial efectivo al Estado [...]» (Casación n.$^{\circ}$ 661-2016-Piura, fundamento jurídico 15); por tanto, será un delito agravado.

Esta diferencia en las categorías tiene incidencia directa al momento de valorar los actos de prueba para sustentar la sentencia. $\mathrm{Si}$ bien (conforme a la casación en referencia inmediatamente anotada) la prueba idónea para probar el perjuicio patrimonial es la pericia contable, este aspecto solo se refiere al elemento objetivo del objeto civil del proceso. La acreditación del resto de elementos objetivos del tipo penal del delito de colusión se vincula con los acuerdos ilícitos que los autores hayan realizado con los cómplices, $\mathrm{y}$ acreditar este aspecto con prueba directa es sumamente difícil.

Asimismo, ¿es posible que la concertación se acredite con prueba directa? Lo es si los acusados confiesan o se someten a una de las formas especiales de colusión del proceso penal, como la colaboración eficaz, según los artículos 472-481 del NCPP (2004).

Por ello, es necesario recurrir al método de valoración de la prueba indiciaria para valorar la prueba directa y, así, acreditar este tipo de delitos, tanto en su modalidad de delito de peligro como en la de delito de resultado.

\subsubsection{Delito de peculado}

En el Código Penal peruano, el delito de peculado tiene cuatro modalidades: una simple, dos agravadas y una culposa.

Así, la modalidad simple se regula de la siguiente manera: «El funcionario o servidor público que se apropia o utiliza, en cualquier forma, para sí o para otro, caudales o efectos cuya percepción, administración o custodia le estén confiados por razón de su cargo será reprimido [...]» (artículo 387 del Código Penal, modificado por el Decreto Legislativo n. ${ }^{\circ} 1243$, publicado el 22 de octubre de 2016). 
La primera modalidad agravada prescribe: «Cuando el valor de lo apropiado o utilizado sobrepase diez unidades impositivas tributarias, será reprimido [...]», y la segunda modalidad agravada: «si los caudales o efectos estuvieran destinados a fines asistenciales o a programas de apoyo o inclusión social, será reprimido [...]».

La modalidad culposa determina: «Si el agente, por culpa, da ocasión a que se efectúe por otra persona la sustracción de caudales o efectos, será reprimido [...]», conforme al artículo 387 del Código Penal, modificado por el Decreto Legislativo n. ${ }^{\circ} 1243$, publicado el 22 de octubre de 2016.

De esta forma, en cuanto a las modalidades dolosas, cuando el funcionario o servidor público se apropia o utiliza caudales (dinero) o efectos (bienes) (Acuerdo Plenario n. ${ }^{\circ}$ 4-2005/CJ-116, párr. 7) para sí u otro, en cuanto a la probanza, también las pruebas son de difícil consecución para el señor fiscal. No obstante, pueden existir pruebas directas, como testigos, pericias, documentos, llamadas telefónicas; pero si no se utilizan las inferencias deductivas, es muy laborioso determinar con claridad lo sucedido, de qué manera se ha apropiado del dinero o ha utilizado los bienes.

En cuanto a la modalidad culposa, pese a que es más fácil de determinar lo sucedido, no es menos cierto que se presentan dificultades para determinar la culpa, lo cual, evidentemente, también representa problemas de demostración, en cuanto deben analizarse las diversas funciones públicas en el Reglamento de Organización y Funciones. Manual de Organización de Funciones y otras obligaciones contenidas en las leyes específicas de los servidores o funcionarios involucrados.

Por ello, es necesario efectuar los ejercicios de valoración de la prueba por el método de valoración de prueba indiciaria. 


\subsubsection{Delitos de corrupción de funcionarios}

\subsubsection{Cohecho propio}

De acuerdo con el artículo 393 del Código Penal, modificado por la Ley n. ${ }^{\circ}$ 30111, publicada el 26 de noviembre de 2013, este delito presenta taxativamente tres modalidades.

La primera se encuentra prevista cuando: «El funcionario o servidor público que acepte o reciba donativo, promesa o cualquier otra ventaja o beneficio, para realizar u omitir un acto en violación de sus obligaciones o el que las acepta a consecuencia de haber faltado a ellas, será reprimido [...]» (Ministerio de Justicia y Derechos Humanos, 2013).

Una segunda modalidad es cuando: «El funcionario o servidor público que solicita, directa o indirectamente, donativo, promesa o cualquier otra ventaja o beneficio, para realizar u omitir un acto en violación de sus obligaciones o a consecuencia de haber faltado a ellas, será reprimido [...]» (Ministerio de Justicia y Derechos Humanos, 2013).

Una tercera modalidad se produce cuando: «El funcionario o servidor público que condiciona su conducta funcional derivada del cargo o empleo a la entrega o promesa de donativo o ventaja, será reprimido [...]» (Ministerio de Justicia y Derechos Humanos, 2013).

En el presente caso también los verbos «aceptar»y «recibir» donativo, promesas, ventaja o beneficio tienen directa implicancia con la probanza de verificar de qué forma ha aceptado o recibido, lo que se dificulta al tratarse de delitos clandestinos.

En cuanto al verbo «solicitar», representa mayor reprochabilidad en el agente; no obstante, el grado más grave es el de «condicionar», porque el funcionario o servidor público viola totalmente sus obligaciones. 
Así, en los tres supuestos legales, difícilmente va a existir prueba directa, ya que nadie otorga un comprobante de la dádiva ilícita que recibe. Pero ello no descarta de manera total un acusado arrepentido.

\subsubsection{Cohecho impropio}

En la forma simple, el funcionario se limita a recibir el donativo ilegal para realizar un acto lícito de su cargo. En contraste, en la segunda modalidad (agravada), la conducta es más osada, dado que el funcionario público solicita, comprometiendo gravemente la función pública. Obviamente, la mayoría de veces, citan al usuario fuera de la entidad pública, por ejemplo, a un restaurante, lugar donde exige la dádiva, con más holgura, sin la presión de la presencia de los demás funcionarios públicos. Asimismo, se verifica que difícilmente existirá prueba directa, más allá de lo dicho por el usuario agraviado, por la exigencia ilegal.

Respecto a la forma simple de este delito, la norma penal dispone: «El funcionario o servidor público que acepte o reciba donativo, promesa o cualquier otra ventaja o beneficio indebido para realizar un acto propio de su cargo o empleo, sin faltar a su obligación, o como consecuencia del ya realizado, será reprimido [...]» (artículo 394 del CP, modificado por el Artículo Único de la Ley n. ${ }^{o} 30111$, publicada el 26 de noviembre de 2013).

En su forma agravada, se prescribe: «El funcionario o servidor público que solicita, directa o indirectamente, donativo, promesa o cualquier otra ventaja indebida para realizar un acto propio de su cargo o empleo, sin faltar a su obligación, o como consecuencia del ya realizado, será reprimido [...]» (artículo 394 del CP, modificado por el Artículo Único de la Ley n. ${ }^{\circ} 30111$, publicada el 26 noviembre 2013).

\subsubsection{Cohecho pasivo específico}

En la modalidad simple de este tipo penal, las autoridades judiciales $\mathrm{y}$ administrativas, haciendo mal uso de sus funciones, reciben 
donativos u otros. En cambio, en la modalidad agravada, las mismas autoridades solicitan el donativo. También es compleja la existencia de prueba directa.

Sobre este tipo penal se ha establecido:

El magistrado, árbitro, fiscal, perito, miembro de Tribunal Administrativo o cualquier otro análogo a los anteriores que bajo cualquier modalidad acepte o reciba donativo, promesa o cualquier otra ventaja o beneficio, a sabiendas que es hecho con el fin de influir o decidir en asunto sometido a su conocimiento o competencia, será reprimido [...] (artículo 395 del CP, modificado por el artículo 1 de la Ley n. ${ }^{\circ} 28355$, publicada el 6 octubre de 2004).

Del mismo modo:

El magistrado, árbitro, fiscal, perito, miembro de Tribunal Administrativo o cualquier otro análogo a los anteriores que bajo cualquier modalidad solicite, directa o indirectamente, donativo, promesa o cualquier otra ventaja o beneficio, con el fin de influir en la decisión de un asunto que esté sometido a su conocimiento, será reprimido [...] (artículo 395 del CP, modificado por el artículo 1 de la Ley n. ${ }^{\circ} 28355$, publicada el 6 de octubre de 2004).

\subsubsection{Cohecho pasivo propio en el ejercicio de la función policial}

Existen tres conductas del efectivo policial (aceptar, solicitar y condicionar); su labor pública, al recibir donativo, promesa, ventaja o beneficio ilegal, hace variar la gravedad, en orden ascendente.

En la praxis, se verifica compleja posibilidad de la probanza de estos ilícitos, por lo que difícilmente existirá prueba directa, salvo la declaración de la víctima.

En cuanto a la actuación delictiva de los miembros de la Policía Nacional del Perú, se regulan las siguientes conductas ilícitas: 
El miembro de la Policía Nacional que acepta o recibe donativo, promesa o cualquier otra ventaja o beneficio, para sí o para otro, para realizar u omitir un acto en violación de sus obligaciones derivadas de la función policial o el que las acepta a consecuencia de haber faltado a ellas, será sancionado [...] (artículo 395-A del Código Penal, incorporado por Decreto Legislativo n. ${ }^{\circ}$ 1351, publicado el 7 de enero de 2017).

También se prescribe:

El miembro de la Policía Nacional que solicita, directa o indirectamente, donativo, promesa o cualquier otra ventaja o beneficio, para realizar u omitir un acto en violación de sus obligaciones derivadas de la función policial o a consecuencia de haber faltado a ellas, será reprimido [...] (artículo 395-A del Código Penal, incorporado por Decreto Legislativo n. ${ }^{\circ}$ 1351, publicado el 7 de enero de 2017).

Y la tercera conducta se regula de la siguiente manera: «El miembro de la Policía Nacional que condiciona su conducta funcional a la entrega o promesa de donativo o cualquier otra ventaja o beneficio, será reprimido [...]» (artículo 395-A del Código Penal, incorporado por Decreto Legislativo n. ${ }^{\circ}$ 1351, publicado el 7 de enero de 2017).

\subsubsection{Cohecho pasivo impropio en el ejercicio de la función policial}

En este caso, en una primera etapa, nos encontramos frente a un actuar lícito, pero en la segunda etapa, se convierte en delictivo: en la primera modalidad (simple), el efectivo policial primero realiza su labor policial y luego, sin solicitar, recibe el donativo ilícito; mientras que en la segunda modalidad (agravada), el efectivo policial primero realiza su labor policial y luego solicita o exige el donativo ilícito. De igual manera, al constituir delitos de naturaleza clandestina, la existencia de prueba directa no será posible, salvo flagrancia. 
Una primera conducta es regulada así:

El miembro de la Policía Nacional que acepta o recibe donativo, promesa o cualquier otra ventaja o beneficio indebido para realizar u omitir un acto propio de su función, sin faltar a su obligación, o como consecuencia del acto ya realizado u omitido, será reprimido [...] (artículo 395-B del Código Penal, incorporado por el Decreto Legislativo n. ${ }^{\circ}$ 1351, publicado el 7 de enero de 2017).

Una segunda conducta dispone que:

El miembro de la Policía Nacional que solicita, directa o indirectamente, donativo, promesa o cualquier otra ventaja indebida para realizar $\mathrm{u}$ omitir un acto propio de su función, sin faltar a su obligación, o como consecuencia del acto ya realizado $\mathrm{u}$ omitido, será reprimido [...] (artículo 395-B del Código Penal, incorporado por el Decreto Legislativo n. ${ }^{\circ}$ 1351, publicado el 7 de enero de 2017).

\subsubsection{Cohecho activo genérico}

Este delito es realizado por particulares, pero involucra la corrupción de funcionarios públicos, puesto que contiene una modalidad agravada en la que, con el poder corruptor del dinero u otro medio, constriñe la voluntad del funcionario público para que realice $\mathrm{u}$ omita actos, violando sus obligaciones.

Asimismo, se manifiesta en otra conducta en la que entrega dinero $\mathrm{u}$ otro medio al funcionario, a fin de que realice sus funciones, conforme a ley. Aparentemente, esta última conducta no revela peligrosidad; sin embargo, genera un antecedente de próximos actos de corrupción entre dicha persona y el funcionario.

Sobre este tipo legal, se dispone que: «El que, bajo cualquier modalidad, ofrece, da o promete a un funcionario o servidor público donativo, promesa, ventaja o beneficio para que realice $u$ omita actos 
en violación de sus obligaciones, será reprimido [...]» (artículo 397 del Código Penal, modificado por el Decreto Legislativo n. ${ }^{\circ} 1243$, publicado el 22 de octubre de 2016).

De otro lado, en el segundo párrafo de la misma norma se expone que: «El que, bajo cualquier modalidad, ofrece, da o promete donativo, ventaja o beneficio para que el funcionario o servidor público realice u omita actos propios del cargo o empleo, sin faltar a su obligación, será reprimido [...]» (artículo 397 del Código Penal, modificado por el Decreto Legislativo n. ${ }^{\circ} 1243$, publicado el 22 de octubre de 2016).

\subsubsection{Cohecho activo específico}

En este tipo penal, se sanciona el actuar del particular, quien trata de corromper a un magistrado que ejerce función jurisdiccional o a una autoridad que cumple funciones administrativas, constituyendo de esta manera la agravante. En cambio, en la segunda conducta, se trata de corromper a un auxiliar jurisdiccional $u$ órgano de prueba (testigo, traductor, perito); por ello es de menor entidad que la anterior.

Además, se sanciona drásticamente la conducta del abogado que trata de corromper al magistrado, fiscal, autoridad administrativa o auxiliar jurisdiccional; si es un abogado que labora en forma individual o asociada, también constituye delito.

Así, la norma regula de la siguiente manera:

El que, bajo cualquier modalidad, ofrece, da o promete donativo, ventaja o beneficio a un magistrado, fiscal, perito, árbitro, miembro de Tribunal Administrativo o análogo con el objeto de influir en la decisión de un asunto sometido a su conocimiento o competencia, será reprimido [...] (artículo 398 del Código Penal, modificado por el Decreto Legislativo n. ${ }^{\circ}$ 1243, publicado el 22 de octubre de 2016). 
En el segundo párrafo, detalla: «Cuando el donativo, promesa, ventaja o beneficio se ofrece o entrega a un secretario, relator, especialista, auxiliar jurisdiccional, testigo, traductor o intérprete o análogo, la pena [...]» (artículo 398 del Código Penal, modificado por el Decreto Legislativo n. ${ }^{\circ} 1243$, publicado el 22 de octubre de 2016).

Y el tercer párrafo prescribe: «Si el que ofrece, da o corrompe es abogado o forma parte de un estudio de abogados, la pena [...]» (artículo 398 del Código Penal, modificado por el Decreto Legislativo n. ${ }^{\circ}$ 1243, publicado el 22 octubre de 2016).

\subsubsection{Cohecho activo en el ámbito de la función policial}

La primera conducta que se sanciona es la del particular que da $u$ ofrece donativo al efectivo policial para que realice u omita actos, violando sus obligaciones. Por ello, la penalidad es agravada. Así, la norma dispone:

El que, bajo cualquier modalidad, ofrece, da o promete a un miembro de la Policía Nacional donativo o cualquier ventaja o beneficio para que realice u omita actos en violación de sus obligaciones derivadas de la función policial, será reprimido [...] (artículo 398-A del Código Penal, incorporado por el Decreto Legislativo n. ${ }^{\circ}$ 1351, publicado el 7 de enero de 2017).

La segunda conducta es de menor entidad, ya que el particular constriñe al efectivo policial para que realice $u$ omita actos sin faltar a sus obligaciones legales:

El que, bajo cualquier modalidad, ofrece, da o promete a un miembro de la Policía Nacional donativo o cualquier ventaja o beneficio para que realice $\mathrm{u}$ omita actos propios de la función policial, sin faltar a las obligaciones que se derivan de ella, será reprimido [...] (artículo 398-A del Código Penal, incorporado por el Decreto Legislativo n. ${ }^{\circ}$ 1351, publicado el 7 enero 2017). 
Esta conducta puede manifestarse, por ejemplo, cuando se deben efectuar lanzamientos luego de una sentencia de ministración de la posesión (en el área penal, la usurpación; en el área civil, el desalojo) en la que ineludiblemente, el efectivo policial debe hacer cumplir la orden del juez penal o civil, según sea el caso.

Así, consideramos que en los delitos de concusión (modalidad de colusión), peculado y corrupción de funcionarios (en las modalidades de cohecho propio, cohecho impropio, cohecho pasivo específico, cohecho pasivo propio o impropio en el ejercicio de la función policial, cohecho activo genérico, cohecho activo específico y cohecho activo en el ámbito de la función policial), difícilmente existirá prueba directa. No obstante, de modo excepcional, puede existir prueba directa, pero, debido a la falta de regulación legal, al valorarla, no es posible emplear el método que suele aplicarse a la valoración de la prueba indiciaria. Ello afecta que el juzgador logre acercarse a la certeza de los hechos y, por tanto, impide acercarse a la verdad procesal.

\section{A MODO DE CONCLUSIÓN}

En el Perú, luego de que se ha debatido sobre las pruebas en el juicio oral, surgen los actos de prueba, que fundamentan la sentencia penal en relación con los delitos de concusión (modalidad de colusión), peculado y corrupción de funcionarios (en las modalidades de cohecho propio, cohecho impropio, cohecho pasivo específico, cohecho pasivo propio o impropio en el ejercicio de la función policial, cohecho activo genérico, cohecho activo específico y cohecho activo en el ámbito de la función policial).

Frecuentemente, no existen pruebas directas. Las pocas que existen deben ser valoradas utilizando las reglas de la «sana crítica», a través de sus elementos: a) la lógica, con sus principios de identidad, contradicción, razón suficiente y tercero excluido; 
b) las máximas de la experiencia (criterios normativos o reglas no jurídicas); c) los conocimientos científicamente aceptados. No se utiliza el razonamiento, el cual suele emplearse para evaluar una prueba indiciaria.

Las pruebas indiciarias, en estos mismos tipos de delitos, son las que más abundan. Por ello, aplicando el método de valoración de la prueba indiciaria, que consiste en el siguiente procedimiento:

a) Que el indicio esté probado.

b) Que la inferencia esté basada en las reglas de la lógica, la ciencia o la experiencia.

c) Que cuando se trate de indicios contingentes, estos sean plurales, concordantes y convergentes, así como que no se presenten contraindicios consistentes.

Está establecido por doctrina que debe existir un hecho base, un hecho consecuencia y un enlace o razonamiento lógico entre estos, de tal forma que, utilizando una inferencia, a través del método lógico-deductivo, en función de indicios plenamente probados (que no son delictivos), se llegará a conocer el hecho consecuencia, el cual se quiere conocer.

Esta forma de analizar la prueba indiciaria presta plenas garantías de acercarnos más a la verdad para emitir sentencia en justicia. Por tal motivo, el método de valoración de la prueba indiciaria debe aplicarse a la valoración de la prueba directa para obtener ese rigor de certeza. 


\section{REFERENCIAS}

Congreso Constituyente Democrático (1993). Constitución Política del Perú. Lima: 31 de octubre de 1993.

Congreso de la República (2004). Ley n. ${ }^{\circ} 28355$. Ley que modifica diversos artículos del Código Penal y de la Ley Penal contra el Lavado de Activos. Lima: 4 de octubre de 2004.

(2013). Ley n. ${ }^{\circ}$ 30111. Ley que incorpora la pena de multa en los delitos cometidos por funcionarios públicos. Lima: 25 de noviembre de 2013.

(2017). Decreto Legislativo n. $^{\circ}$ 1351. Decreto Legislativo que modifica el Código Penal a fin de fortalecer la seguridad ciudadana. Lima: 6 enero de 2017.

Corte Suprema de Justicia de la República (2005). Acuerdo Plenario n. ${ }^{\circ}$ 4-2005/CJ-116. Definición y estructura típica del delito de peculado, artículo 387 del Código Penal. Lima: 30 de septiembre de 2005.

(2006). Acuerdo Plenario n. ${ }^{\circ}$ 1-2006/ESV-22. Pleno Jurisdiccional de las Salas Penales Permanente y Transitorias. Lima: 13 de octubre de 2006.

(2010). Acuerdo Plenario n. ${ }^{\circ}$ 3-2010/CJ-116. VI Pleno Jurisdiccional de las Salas Penales Permanente y Transitorias. Lima: 16 de noviembre de 2010.

(2012). Casación n. ${ }^{\circ}$ 281-2011-Moquegua, emitida por la Sala Penal Permanente de la Corte Suprema de Justicia de la República del Perú. Lima: 16 de agosto de 2012.

(2017). Casación n. ${ }^{\circ}$ 661-2016-Piura, emitida por la Sala Penal Permanente y Transitoria de la Corte Suprema de Justicia de la República del Perú. Lima: 11 de julio de 2017.

(25 de octubre de 2017). I Pleno Jurisdiccional Casatorio de las Salas Penales Permanente y Transitorias. Sentencia Plenaria Casatoria n. ${ }^{\circ}$ 1-2017/CIJ-433. Alcances del delito de lavado de 
activos y estándar de prueba para su persecución y condena, de fecha 11 de octubre de 2017. Diario Oficial El Peruano, separata especial, (1058), pp. 7920-7942.

Ferrer, E. y Pelayo, C. (2014). Artículo 1. Obligación de Respetar los Derechos. Capítulo I. Enumeración de deberes. En Steiner, C. y Uribe, P. (eds.), Convención Americana sobre Derechos Humanos. Comentario (pp. 42-68). La Paz: Plural Editores.

Ibáñez, J. (2014). Artículo 8. Garantías Judiciales. Capítulo II. Derechos civiles y políticos. En Steiner, C. y Uribe, P. (eds.), Convención Americana sobre Derechos Humanos comentada (pp. 207-254). La Paz: Plural Editores.

Ministerio de Justicia y Derechos Humanos (2004). Nuevo Código Procesal Penal. Decreto Legislativo n. ${ }^{\circ}$ 957. Lima: 29 de julio de 2004.

Poder Ejecutivo (1991). Decreto Legislativo n. ${ }^{\circ}$ 635. Código Penal. Lima: 8 de abril de 1991.

(2016). Decreto Legislativo n. ${ }^{\circ}$ 1243. Decreto legislativo que modifica el Código Penal y el Código de Ejecución Penal a fin de establecer y ampliar el plazo de duración de la pena de inhabilitación principal, e incorporar la inhabilitación perpetua para los delitos cometidos contra la Administración Pública, y crea el Registro Único de Condenados Inhabilitados. Lima: 22 de octubre de 2016.

Tribunal Constitucional (2003). Sentencia del Tribunal Constitucional. Expediente n. ${ }^{\circ}$ 010-2002-AI/TC (2002). Lima: 3 de enero de 2003.

(2012). Sentencia de Tribunal Constitucional. Expediente n. ${ }^{\circ}$ 017-2011-PI/TC. Lima: 3 de mayo de 2012.

Tribunal Constitucional de España (1999). Sentencia 197/1999. Madrid: 25 de octubre de 1999. Recuperado de http://hj. tribunalconstitucional.es/es-ES/Resolucion/Show/3939 